\title{
La presencia española en el norte de Sulawesi durante el siglo XVII. Estudio del asentamiento español en el norte de Sulawesi ante la oposición local y la amenaza holandesa $(1606-1662)^{1}$
}

por

Antonio C. Campo López²

UNED

La soberanía española sobre las islas Molucas (1606-1662) dio lugar a un episodio poco conocido en la historia española, la presencia de soldados españoles en el norte de la actual isla de Sulawesi. La conquista de las Molucas en 1606 inició un periodo de frecuentes relaciones entre los españoles de las Molucas y las tribus de la cercana isla de Sulawesi. Durante varias décadas se firmarán alianzas y habrá una pequeña colonia española en el norte de Sulawesi. La lejanía del territorio y la escasez de recursos imposibilitarán la consolidación de una colonia española y antecederá la colonización holandesa de este territorio. No obstante, lejos de ser un episodio aislado, esta presencia española tuvo una continuidad temporal que hizo que durante casi siete décadas, soldados y religiosos españoles viajaran y residieran en este territorio tan alejado del centro de poder de Manila.

Palabras Clave: Manado; Tondano; Célebes; Sulawesi; Ternate; Siao.

Cómo citar este artículo / Citation: Campo López, Antonio C., "La presencia española en el norte de Sulawesi durante el siglo XVII. Estudio del asentamiento español en el norte de Sulawesi ante la oposición local y la amenaza holandesa (1606 - 1662)", Revista de Indias, LXXVII/269 (Madrid, 2017): 51-80, doi:10.3989/revindias.2017.002.

La presencia española en Sulawesi se explica a partir de la soberanía española sobre las islas Molucas. Aunque la llegada de los españoles a Asia

${ }^{1}$ Quisiera agradecer al Dr. Carlos Martínez Shaw por su gran ayuda y asesoramiento para la elaboración de este trabajo.

2 antoniocampolopez@gmail.com ORCID iD: http://orcid.org/0000-0002-5246-8559. 
vino motivada con el objetivo del control de las especias de este archipiélago, el descubrimiento de los territorios que formarán Filipinas hizo que pasaran a ser un objetivo no prioritario, asumiéndose la soberanía lusa sobre ellas. Los esfuerzos de las autoridades españolas durante el último cuarto del siglo XVI se centraron en la creación y consolidación del nuevo territorio colonial filipino.

A inicios del siglo XVII el dominio español en Filipinas se encuentra en buen estado. Manila se ha consolidado como un importante enclave comercial conectado, gracias a los mercaderes chinos, con el tráfico comercial asiático. Los galeones de Nueva España, además de recursos para la colonia, proporcionan una red de intercambio comercial entre Asia y América de gran beneficio para la ciudad de Manila. Con respecto a las Molucas, la soberanía lusa empezaba a correr grave peligro. La lejanía de sus enclaves de Goa y Malaca, las hacía incapaces de resistir con garantía a las amenazas del sultán de Ternate y de los holandeses, que desde inicios del XVII empezaron a establecerse en estos territorios. Esta llegada holandesa a las Molucas desencadenará una importante campaña militar desde Manila: la expedición de Pedro de Acuña de 1606. Su éxito provocará que las Molucas pasen a estar tuteladas desde Manila y la nueva frontera meridional del dominio español asiático quede establecida mucho más al sur de Mindanao. Los fuertes del Maluco albergarán una presencia continuada de fuerzas españolas durante los próximos 56 años. El inicio del gobierno español sobre el Maluco tendrá su lógica influencia en los territorios circundantes, especialmente en la gran isla de las Célebes, la llamada isla de Mateo por las fuentes españolas y actual isla indonesia de Sulawesi. Un gran territorio al este de Ternate, accesible a solo unos días de navegación, que de ser un territorio al que nunca se le había prestado mucha atención, visitándose de forma ocasional cuando los vientos forzaban a hacer escalas involuntarias a las naves de la ruta Molucas-Mindanao, pasará a convertirse en una zona de interés estratégico.

\section{El norte de las Islas Célebes a inicios Del XVII}

A principios del XVII el norte de Sulawesi era un territorio habitado por diferentes pueblos, que a pesar de sus vínculos culturales comunes estaban lejos de presentar grandes estructuras de organización, a diferencia de lo que ocurría en el sur con el sultanato de Macasar, la entidad política más importante de Sulawesi, y centro de una importante red comercial asiática. Pese a ello, la soberanía de Macasar no llegaba al resto de la isla, sin ni siquiera ejercer una gran influencia sobre unos reinos del norte que incluso tenían unas 
vinculaciones más estrechas con el sur del archipiélago filipino que con el resto de su propia isla ${ }^{3}$.

El norte de Sulawesi distaba de ser un territorio unificado bajo un poder central. Aunque estaba conformado por numerosas tribus independientes, las fuentes españoles siempre hacen mención a tres reinos principales. Esto no quiere decir que éstos fuesen capaces de controlar todo el norte de la isla; su mayor mención en las fuentes se debe a ser los reinos de mejor acceso desde la costa.

El primer reino y el más nombrado en las fuentes españolas es el de Manado, en torno al territorio situado en la actual ciudad del mismo nombre. Al asentarse cerca de un puerto natural fue el primer reino con el que contactaron las expediciones españolas procedentes de Ternate. La soberanía del rey de Manado se desplegaría sobre un pequeña zona en torno a las actuales poblaciones costeras de Manado y Amurang. Fuera de la zona costera, el interior estaba habitado por diferentes poblaciones o tribus independientes que no aceptaban la supremacía del cacique de Manado, a quien consideraban más bien como un igual. El enfrentamiento entre ellas era continuo, pudiéndose hablar de un estado de guerra crónico y de gran violencia ${ }^{4}$. El conjunto de todo este territorio ha recibido la denominación de Minahasa, aunque las fuentes españoles utilizan siempre el nombre de Manado para referirse al mismo. Minahasa abarcaría el territorio entre ambas costas, entre los actuales mares de Sulawesi y Molucas y al norte del ecuador, y englobaría diferentes tribus, cada una de ellas con su respectiva área de influencia, controlando un territorio no muy amplio en torno a su poblado principal. La complicada orografía del territorio, marcada por numerosos valles y montañas, facilitaría esta fragmentación. Los españoles remarcaban mucho la dicotomía entre costa y montaña. La costa albergaría los reinos principales con un pasado de contactos y comercio con los primeros europeos, accesibles a la llegada de embarcaciones por mar y ríos, y abiertos a colaborar y establecer alianzas con los españoles a cambio de ayuda militar frente a un tercero. Por contra, el interior sería territorio de tribus menos accesibles y más reacias a cualquier intento de colaboración. Sin embargo, entre estas tribus de las montañas del interior, que serán las denominadas como olifares o alfuros por los españoles, hay que destacar la población más grande de Minahasa, el llamado pueblo de

3 Wigboldus, 1987: 64. Este hecho lo comprobamos en el campo de la lingüística. Los lenguajes de los dos grupos más importantes del norte de Sulawesi, Minahasa y Bolang-Mongodow, son los únicos que pertenecen al grupo filipino.

${ }_{4}$ Colín, 1663: 110. «Son en ella crueles, pues matan a todos los rendidos sin concederles vida, ni prisión». 
Tondano o La Laguna, con más de 700 casas según las fuentes españolas ${ }^{5}$, en torno al actual lago del mismo nombre, y que con el paso de los años acabó siendo la población que mayor fidelidad mostró al bando hispano, manteniendo la alianza con los españoles, aun cuando los holandeses ya se habían aliado y establecido en Manado. Hasta seis pueblos encontramos mencionados en las fuentes españolas. Cada uno con su correspondencia actual y todos localizados en el interior del norte de Sulawesi: Cale (Kali), Cacascasen (Kakaskasen), Tomun (Tomohon), Sarranson (Sarongson), Tonbani (Tanawangko) y Las Quemas (Kema).

\section{Mapa 1. Norte De Sulawesi}
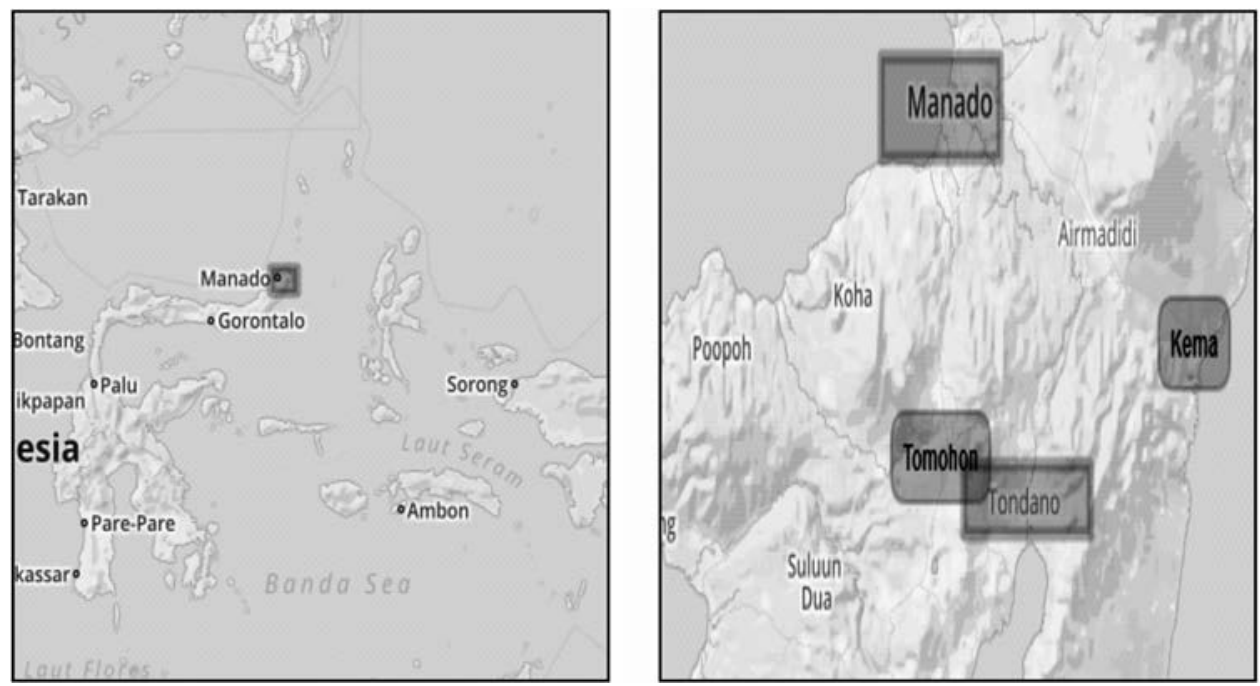

Destacadas algunas de las poblaciones con presencia española.

Al sur de Manado, las fuentes también mencionan dos reinos más. Por una parte, Cauripa (Kaidipán), que era el reino al que se llegaba remontando un río desde Manado: siguiendo la costa sería su frontera meridional, disponiendo también de puerto. Por otra parte, Bool (Bulan o Bohol), a tres días al sur de Cauripa, que era el más lejano de los tres, pero el único poseedor de sali-

5 Relación de Fr. Blas Palomino sobre Manados, Manados, 23 de junio de 1619, Archivo Franciscano Ibero-Oriental, Madrid (AFIO), caja 21, Filipinas Varios, leg. 11, fol. 4. 
tre y capaz de fabricar su propia pólvora ${ }^{6}$. Según avanza el siglo XVII irá aumentando su hegemonía en la zona, conformando lo que en el futuro se denominaría Bolaang Mongodow?

El grueso de las visitas y de la influencia española se desarrollará en la zona más septentrional y más accesible desde Molucas, la perteneciente a la región de Manado-Minahasa, siendo Manado el destino inicial y la puerta de entrada de las embarcaciones españolas. Desde su poblado, que albergará una guarnición española, se iniciarán las penetraciones al interior.

Entre el último punto de abastecimiento español en Zamboanga (punta occidental de la isla de Mindanao) y la isla de Ternate se desplegaba un cinturón de islas que conocerían los navegantes españoles de la ruta Manila-Molucas. Las escalas en estas islas, voluntarias o no, fueron creando una serie de contactos que se fueron intensificando de forma progresiva durante el siglo XVII. Vamos a mencionar las que albergaron presencia española o tuvieron un papel activo en los conflictos militares entre los poderes de la zona (mapa 2).

\section{MAPA 2. IsLas del NORTE De Sulawesi}
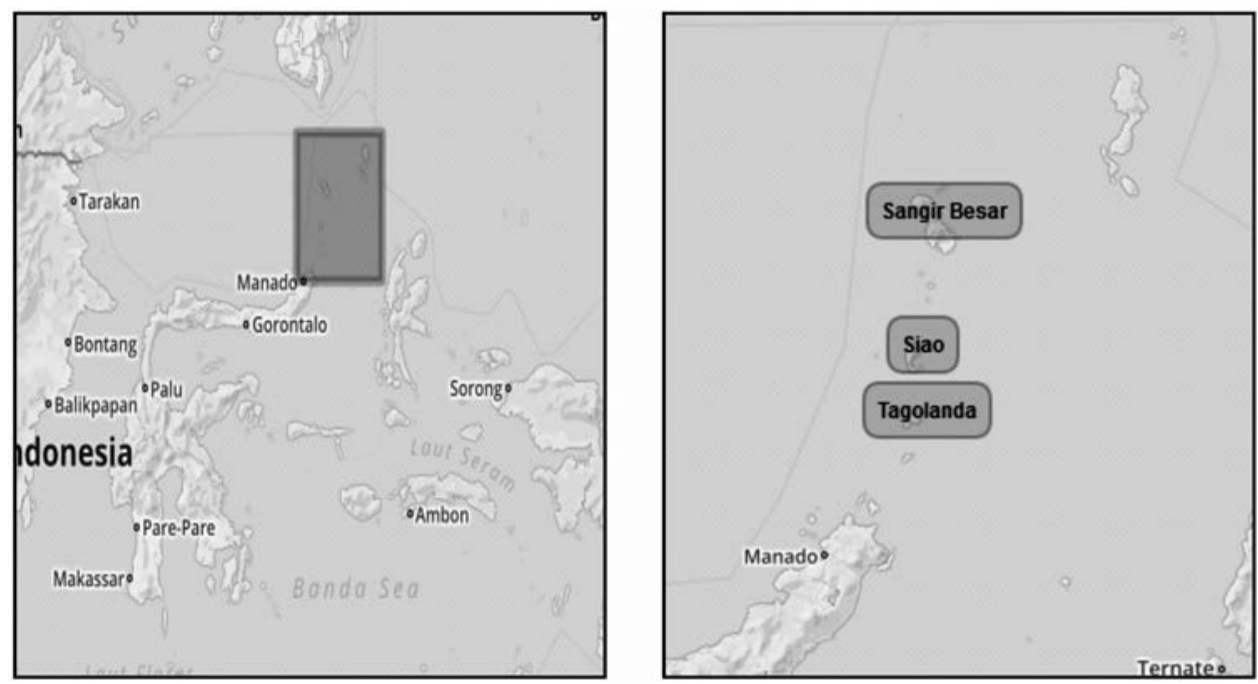

6 Juan de la Concepción, 1788, vol. 1: 126.

7 Colín, 1663: 109. Bolang sería el nombre local para este reino de Bool, mientras que Mongodow correspondería a Mogondo, en el interior. 
Siao

El reino de Siao fue el aliado por excelencia de los españoles de las Molucas. Una alianza firme y duradera, que se remontaba al gobierno de Gómez Pérez Dasmariñas. En 1593, cuando el sultán de Ternate ocupó la fortaleza de la isla vecina de Sangir, el rey de Siao (Don Gerónimo), cristiano convertido por los jesuitas desde el Maluco, navegó hasta Manila buscando la ayuda española ${ }^{8}$. La embajada obtiene resultados, firmándose un acuerdo de colaboración mutua, que pasará también a sus sucesores. Por dicha alianza el rey de Siao acepta la llegada de misioneros y da licencia para construir una fortaleza que albergue soldados españoles. El asesinato de Pérez Dasmariñas a manos de mercenarios chinos al comienzo de una expedición al Maluco impedirá su materialización. No obstante, su hijo y sucesor, Luis Pérez Dasmariñas, enviará un pequeño grupo, creándose el vínculo que posibilitará a los españoles tener una base de apoyo entre Molucas y Mindanao ${ }^{9}$. Su firme alianza con Manila provocará que Siao sea víctima de ataques de los enemigos de España: los holandeses, conocedores de su importancia estratégica como escala fundamental en la ruta del socorro del Maluco, acometerán acciones de gran virulencia, como la del año 1615, cuando deportan a gran parte de sus habitantes a sus plantaciones de las islas Banda (Palau Ay $)^{10}$. Este hecho nos ayudará a entender la firmeza de la alianza con España, así como su gran recelo y enemistad hacia los holandeses. La isla de Siao (Pulau Siau) tiene el mérito de ser el último territorio abandonado por los españoles, perdurando la alianza con España aun cuando ya se había consumado la evacuación de las Molucas ${ }^{11}$. Será un epílogo de 15 años, marcando el año de 1677 la fecha de salida de los últimos españoles del territorio al sur de Filipinas con la evacuación del fuerte de Santa Rosa ante la presión militar del sultán de Ternate y sus aliados holandeses.

8 Ibidem: 321. Juan de la Concepción, 1788, vol. 2: 197.

9 Colín, 1663: 330.

10 Memoria y Relación e historia verdadera de lo sucedido en las Islas Molucas 16091619, Gregorio de San Esteban, AFIO, caja 21, leg. 12, fol. 72. Calcula la deportación en más de 500 personas, incluyendo mujeres: la mayor parte de ellos acabarán siendo asesinados o esclavizados.

11 Carta de Francisco Montemayor sobre reyes de Ternate, Siam, Tabucán, Manila, 12 de junio de 1678, Archivo General de Indias, Sevilla (AGI), Filipinas, 23, R. 17, N. 55, fol. 3. 


\section{Meaos}

Vasallas de Ternate son el conjunto de islas al norte de Sulawesi y más cercanas a Manado. Si Siao fue el aliado por excelencia de los españoles, en este conjunto de islas encontramos al gran enemigo: la isla de Tagolanda o Taolán (Pulau Thulandang), lugar de martirio de franciscanos españoles ${ }^{12}$. Su arraigado sentimiento musulmán y su alianza con los holandeses imposibilitarán que los españoles establezcan fuertes en estas islas.

\section{Sangir}

Las islas Sangir son el conjunto de islas situadas más al norte de las anteriores que albergan diferentes reinos, siendo Calonga y Tabuca los dos más importantes, ambos en la isla principal del archipiélago (Sangir Besar, Pulao Sangihe). Su protagonismo se desarrollará en la década de los 40 por la exitosa campaña de evangelización franciscana. Aliados de España, su posición cercana al norte de Sulawesi permitió a españoles con problemas en Manado valerse de ellas para lograr el regreso a Molucas. La evacuación española de las Molucas de 1662 conllevó el abandono del presidio de Tabuca, una pequeña fuerza de una decena de soldados destinados a proteger a los nativos cristianos de los ataques de los vecinos musulmanes ${ }^{13}$.

\section{Ternate, Puerta de SAlida Para las EXPEDiciones a SulaWesi}

El territorio de las Molucas quedó bajo soberanía portuguesa en virtud del Tratado de Zaragoza de $1529^{14}$, pero a partir de la unión de los reinos ibéricos de 1580 y con la fundación nueve años atrás de la ciudad de Manila, las viejas aspiraciones españolas al control de las islas de las especias vuelven a parecer factibles. La influencia española se va ir incrementado de formar progresiva: desde Manila se organizan expediciones, que pese a ser de ayuda

12 San Antonio, 1728: 376. Antonio de Santa Ana, estando de misión en Manado, en 1610 fue apresado en el río Cauripa para ser llevado a Tagolanda, donde fue martirizado.

13 AGI, Filipinas, 23, R. 17, N. 55, fol. 3.

14 Spate, 2006: 147. Por el Tratado de Zaragoza de 1529, Carlos I cede los derechos sobre las Molucas al rey de Portugal Juan III, con una cantidad de compraventa de 350.000 ducados. Aunque en caso de devolver el pago, los derechos sobre estos territorios volverían a ser españoles. Esta posibilidad no se llevó nunca a efecto. 
empiezan a ser vistas con recelo por las autoridades portuguesas ${ }^{15}$. A inicios de la nueva centuria, en 1602, los portugueses de Molucas viven sus momentos de mayor debilidad. La ayuda holandesa al sultán de Ternate es una amenaza real a su soberanía, por lo que el capitán de Tidore, Rui Gonzalez de Siqueira, se ve obligado a pedir la ayuda española. La respuesta no se hace esperar y en 1603 se arma una expedición comandada por Juan Juárez de Gallinato en alianza con el portugués Hurtado de Mendoza que sale desde Goa. Pese a estar muy cerca de la victoria, la falta de entendimiento entre las naciones ibéricas no logra culminar el asedio sobre Ternate (el recelo luso era evidente sabiendo que la victoria significaría sustituir Goa por Manila como referencia de mando para las Molucas).

Tras esta serie de fracasos continuados, y toda vez que los holandeses ya se habían establecido en las Molucas, en 1606 se pone en marcha la campaña que va a dar inicio a la presencia española en este territorio: la gran expedición de Pedro de Acuña, la mayor empresa militar reunida hasta el momento, con más de 3.000 expedicionarios (mitad españoles y mitad nativos filipinos). Las autoridades españolas deciden prescindir de la colaboración portuguesa y se consigue la toma completa de Tidore y gran parte de Ternate. Las Molucas pasan a ser gobernadas por España con una fuerza militar estable de 600 soldados ${ }^{16}$. La victoria logra detener momentáneamente el empuje holandés y conlleva sustituir la soberanía portuguesa por la española, aunque no consigue expulsar a los holandeses, fuertemente asentados en estas islas ${ }^{17}$. Comenzará una verdadera guerra de posiciones, con los enemigos europeos separados a

15 En 1582 se manda la expedición de Juan Ronquillo que fracasa en la toma de Ternate. En 1584, se envía otra expedición al mando de Juan Morón para ayudar al capitán portugués de Tidore en la reconquista de Ternate, pero también termina en fracaso. La siguiente, de Gómez Pérez Dasmariñas en 1593, aunque más ambiciosa, fracasó antes de llegar a su destino por el asesinato del gobernador a manos de mercenarios chinos al poco de salir Manila.

16 Morga, 1609: 246. 500 en Ternate al mando del nuevo gobernador del Maluco Juan de Esquivel, más 100 en Tidore al mando del capitán Alarcón.

17 En Ternate tenían tres fuertes: el principal Fort Orange (Fuerte Malayo, 1607), Fort Willemstad (Fuerte Tacome, 1609) y Fort Hollandia (Fuerte San Juan de Toluco, conquistado a los españoles en 1612). En Tidore también permanecerán casi una década (entre 1613 y 1622). En 1608 ya disponen de 3 fuertes en Makian (la isla que más clavo proporciona); en 1609 capturan el fuerte español de Bacham y establecen otro en Motir. Los españoles controlarán el sur de Ternate con su capital en Ciudad del Rosario, la isla de Tidore (con varios fuertes, siendo Tohula o Santiago de los Caballeros el principal) y otros en la isla de Gilolo (fuerte Sabugo en la actual isla de Halmahera) y Morotai (San Juan de Tolo), las islas más grandes de la zona pero las menos pobladas y con pocas especias, que acabarán abandonando para concentrarse en Ternate y Tidore. Para un estudio de los fuertes españoles en Tidore, ver Ramerini, 2008. 
muy pocos kilómetros, y en la que los holandeses parecen tener mayor empuje, gracias al periódico envió de embarcaciones desde sus puertos del mar del Norte, que a través del cabo de Buena Esperanza llegan directamente a Asia.

A principios del siglo XVII, las islas de la especias ya habían empezado a ser visitadas por barcos holandeses ${ }^{18}$. La pujanza económica de la nueva nación posibilitó el envío regular de flotas con el objetivo del control de las especias. Consiguen expulsar a los portuguesas en las Molucas del Sur (Banda y Ambon) y hacer frente a los españoles en las Molucas del Norte, fundando en 1607 el fuerte Orange (fuerte Malayo en las fuentes españolas), que será su posición principal cerca de Talangame, el mejor puerto de Ternate, y a 10 kilómetros al norte de Ciudad del Rosario o Nuestra Señora del Rosario en Ternate, el enclave español más importante en las Molucas (actual Kastela), residencia del sultán (Gamalama), destino final del socorro procedente de Manila y puerta de salida a los territorios cercanos, sobre todo al oeste, donde se encuentra la cercana gran isla de Mateo (Sulawesi), cuyos pueblos tenían unos fuertes vínculos históricos con la isla de Ternate.

\section{La relación de vasallaje Ternate-Sulawesi}

La llegada europea a las Molucas se hace sobre unas sociedades con ciertos niveles de desarrollo y jerarquía. En virtud de las redes comerciales asiáticas y la existencia de productos de gran demanda, Ternate era el sultanato más poderoso de la zona. Viendo la geografía del archipiélago no era la isla más grande, pero sí era la que gozaba del vasallaje de los territorios cercanos. Ya Argensola en su Conquista de las Molucas, enumera todos los territorios tributarios del rey de Ternate (al que denomina Emperador del Archipiélago) ${ }^{19}$, entre los que se incluyen los reinos septentrionales de la isla de Mateo, llegando su influencia incluso hasta Mindanao ${ }^{20}$.

La toma de Ternate proporcionaría información acerca de sus reinos tributarios y posibilitaría el envío de expediciones a estos nuevos territorios vecinos. Los portugueses ya habían visitado algunos de estos reinos tributarios

18 Laarhoven y Pino Wittermans, 1985: 485-504. La primera presencia es del año 1595 con la llegada de Cornelius de Houtman a Java. Previo a su viaje Cornelius de Houtman fue enviado a Lisboa para recabar información de la ruta portuguesa de acceso a las especias.

19 Leonardo de Argensola, 1609: 81-82.

20 Ibidem: 222. Morga, 1609: 58. El sultán de Ternate envió soldados para ayudar a los locales en sus luchas contra los españoles de la expedición de Esteban Rodríguez de Figueroa de 1596. 
e incluso habían acompañado al sultán de Ternate en alguna visita, como la que hizo al rey de Manado en $1565^{21}$. Los españoles son conocedores de esta realidad y, poco después de la conquista de las Molucas, acometen la primera expedición a Sulawesi: el 10 de octubre de 1606 se dirige a la isla de Mateo una expedición al mando de Cristóbal Suárez ${ }^{22}$. Los reinos de Sulawesi, como tributarios del sultán de Ternate, ven la llegada de los españoles como una oportunidad para mejorar su posición frente a los vecinos y no tardan en pedir armas, pólvora y balas. Si el sultán de Ternate se somete y jura obediencia a España, a los ojos de los reinos del norte de Sulawesi aparece un nuevo poder en escena, el español, con el que poder negociar, aunque esto sólo se producirá siempre y cuando beneficie a sus intereses.

\section{Las eStrategias ESPAÑolas SOBRE SulaWESI}

\section{Económicas: bastimentos y comercio}

Las Molucas, a pesar de su fama como islas de la especiería, no tenían recursos suficientes para alimentar a toda la nueva población española que iba llegando para cubrir los diferentes fuertes dispersos por las islas del Maluco. Esta carestía fuerza a tener que buscar recursos fuera de ellas, y la gran isla de las Célebes aparece como una solución para resolver el déficit alimenticio del Maluco. El norte de Sulawesi no era territorio productor de especias, pero tenía una gran tradición en el cultivo del arroz. Para los españoles el acceso al arroz de Sulawesi suponía tener cubierta gran parte de las necesidades alimenticias. Sin embargo su acceso no era fácil, pues el arroz no se producía en la costera Manado: los campos de arroz se encontraban en territorio de los pueblos del interior y, antes que para comer y comerciar, se cultivaban para fines religiosos, siendo su finalidad primera la de servir de ofrenda a sus dio$\operatorname{ses}^{23}$. La producción sobrante de estos sacrificios sería a la que accedían los españoles, y no era gratis, debiendo ofrecer armas y ropa a cambio de ello ${ }^{24}$. Si el arroz no se lograba en las Célebes, debía ser traído desde las Filipinas,

21 Santos Hernández, 1977: 531-535. El Padre Magalhães visita Manado acompañando al sultán de Ternate. Los jesuitas permanecen casi 40 años 1568-1608 en Manado. Con la llegada de los españoles serán reemplazados con los franciscanos.

22 Leonardo de Argensola, 1609: 383.

23 AFIO, caja 21, leg. 11, fol. 2.

24 Sancho Rayón, 1868: 223. En una carta de 1614 al gobernador Jerónimo de Silva nos cuenta cómo, por la falta de comida en las Molucas, Juan Martínez de Liédena va a Manado para conseguir arroz y sagú a cambio de ropa. 
en una ruta no muy accesible, puesto que no se hacía directamente, sino teniendo una escala en Siao, donde se almacenaba a la espera de embarcaciones más pequeñas que lo distribuían entre los diferentes fuertes de las Molucas ${ }^{25}$. Junto al arroz, el sagú constituía el complemento básico e indispensable en la dieta de los españoles. Su elaboración en forma de harina, tomando como base el almidón presente en los troncos de las palmeras, proporcionaba el recurso para sustituir la ausencia de arroz ${ }^{26}$. Con buenas provisiones de arroz y sagú se cubrirían las necesidades básicas de alimentación para los residentes en Molucas. El arroz había que traerlo de Manila, Minahasa o Macasar, y el sagú, aunque presente en las Molucas, no siempre tenía fácil acceso con las fuerzas holandesas situadas a escasos kilómetros de las posiciones españolas.

Las primeras expediciones tras la toma de Ternate, obedecen más a la búsqueda de alimentos que a los deseos de conquista ${ }^{27}$. En una relación de 1610 que el gobernador de las Molucas Cristóbal de Azcueta envía a don Juan de Silva, tenemos el informe de este viaje, que nos confirma que su objetivo principal era la búsqueda de alimentos. El champán consigue volver a Ternate tres meses y medio después con provisiones de sagú para alimentar un mes a toda la población del Rosario, que entre españoles, portugueses, mestizos y nativos-mardicas se contabilizaba en unas 1.300 personas $^{28}$.

Por tanto, los primeros viajes hechos desde Ternate obedecen a la búsqueda de soluciones a unos problemas de logística causados por la llegada de una población española hasta ahora nunca vista en estas islas. El socorro que se enviaba desde Manila tardaba mucho en llegar y era insuficiente. Gracias a los viajes a Sulawesi se podían solucionar temporalmente las carencias del socorro del Maluco ${ }^{29}$.

Desde el punto de vista comercial, con respecto a Manado, también se llegaron a plantearse políticas relacionadas con el comercio del clavo. Se pensó en el establecimiento de una factoría española para intermediar en el envío de clavo a la India. Pero fue más bien un hecho aislado, no existiendo una estrategia comercial a largo plazo. El mandar clavo a la India era un recurso extraordinario para obtener lo que faltase en Molucas, que era mucho

25 Ibidem: 183.

26 Fernández Navarrete, 1676: 326. «Compramos allí mucho Sagú (...) es el corazón de unas palmas, remojándose hace harina amarilla. De esta se hacen una tortillas, que sirven de pan a aquella gente, y nosotros nos sustentamos con aquello seis meses».

27 AFIO, caja 21, leg. 12, fol. 34.

28 Carta del virrey Luis de Velasco, el joven, México, 4 de abril de 1610, AGI, México, 28, N. 2, fol. 59. Además del sagú, el viaje también proporcionó una buena provisión de carne y gallinas.

29 Idem. 
debido a, como ya dijimos, la carestía crónica de este territorio y la poca ayuda que se recibía de Manila. El gobernador Fajardo de Tenza en carta al rey dice que el clavo que escapaba al control de los holandeses y que se recolectaba directamente en Molucas no era suficiente para el gran comercio, y el poco que había se utilizaba para proveerse de arroz y otras $\operatorname{cosas}^{30}$ (como la compra de esclavos en Malaca para las galeras del Maluco, ya que allí se adquirían a mejor precio $^{31}$ ).

La toma de las Molucas no conllevó un gran cambio en el comercio de las especias. De la parte ibérica se mantuvo la gestión portuguesa a través de Malaca e India y no de Filipinas ${ }^{32}$. El único producto de valor de las Molucas, el clavo, era gestionado por los comerciantes portugueses de las islas Molucas y no debía ser mucho, puesto que los holandeses, en sus intentos de hacerse con el monopolio, controlaban las zonas de mayor producción de las islas. Su control pasaría por la derrota y expulsión de los holandeses de las Molucas, como así lo expresa el gobernador del Maluco Pedro de Heredia al inicio de su misión en $1622^{33}$ y lo vuelve a señalar el gobernador de Filipinas Niño de Távora, que en carta al monarca de 1628 dice que hacerse con el comercio de clavo que tienen los holandeses ayudaría a sufragar los gastos de las Molucas $^{34}$. Pero este objetivo nunca se logró, más bien fue todo lo contrario, siendo la $\mathrm{VOC}^{35}$ la que cada vez arrinconó más al español en estos territo$\operatorname{rios}^{36}$. La falta de productos de alto valor en el norte de Sulawesi no motivaría un gran interés del territorio a nivel comercial: su interés económico más

30 Carta de Alonso Fajardo de Tenza sobre asuntos de gobierno, Manila, 31 de julio de 1621, AGI, Filipinas, 7, R. 5, N. 64, fol. 10. Lo dice el gobernador Cristóbal Azcueta a don Juan de Silva. "con el envío de este champán se ha aliviado algo aunque poco pero espero en Dios que con otro viaje que haga nos sustentemos hasta que V. S. nos socorre».

31 Rodríguez, 1986, vol. 18: 260.

32 Centenero de Arce y Terrasa Lozano, 2008: 248. Aunque la conquista de Acuña hizo que dentro del gobierno español se viese legítimo conducir el clavo a través de Filipinas, Felipe III no lo aprobó.

33 Carta de Pedro de Heredia a Alonso Maldonado sobre Terrenate, México, 15 de febrero de 1622, AGI, Filipinas, 39, N. 5, fol. 1.

34 Carta de Niño de Távora sobre la expedición a Isla Hermosa, Manila, 4 de agosto de 1628, AGI, Filipinas, 30, N. 12, fol. 16. Ante la dificultad de expulsar a las fuerzas holandesas y el poco clavo que se obtiene en Tidore, propone al menos la toma de la isla de Makián para poder obtener réditos del comercio de su clavo. Para tal objetivo pide un socorro extraordinario de 500 hombres (300 de Manila y 200 de Nueva España).

35 VOC, del holandés Verenigde Oostindische Compagnie (Unión de Compañías de las Indias Orientales). Compañía comercial de capital mixto, surgida en 1602 con el objetivo de controlar el comercio con Asía.

36 Sánchez Pons, 2013: 107-132. 
directo vendría sobre todo por los productos de primera necesidad que faltaban en Molucas, principalmente el arroz.

\section{Religiosas: franciscanos, jesuitas}

Las órdenes religiosas fueron las entidades que más claramente tuvieron marcados sus objetivos en estos nuevos territorios. Con la finalidad del logro de conversiones enviaron a varios de sus miembros en las expediciones comerciales o militares. El siglo XVI, asociado a la presencia portuguesa es el norte de la isla, es protagonizado por los jesuitas. Por contra, en el siglo XVII el relevo del poder portugués por el español también conlleva que una nueva orden religiosa se establezca en las Molucas y adquiera un gran protagonismo: los franciscanos. Los miembros de la orden de San Francisco serán visitantes asiduos del norte de Sulawesi con el siempre difícil objetivo del logro de conversiones. La dicotomía jesuita-franciscana será de una gran rivalidad, una verdadera lucha de competencias sobre el derecho de evangelización de esta tierra, con el trasfondo de la confrontación hispano-portuguesa sobre la legitimidad de la soberanía sobre estos territorios. Los jesuitas se basarán en haber sido los primeros en llegar, frente a los franciscanos, que vinculan su derecho en paralelo al inicio de la soberanía española sobre las Molucas ${ }^{37}$.

En 1611 el gobernador del Maluco Cristóbal de Azcueta favorece a la orden de San Francisco otorgándole el derecho de prédica y limosnas sobre los territorios de Sulawesi, lo que conllevaba la facultad y licencia para «que pudiese tomar y fabricar casas y conventos de su orden en dicha isla» ${ }^{38}$. El conocimiento de nuevas posibilidades de conversión hizo que la apuesta franciscana por la evangelización de Sulawesi fuera muy fuerte y arriesgada. Así, ya la primera misión franciscana de 1610 se saldó con los martirios de Antonio de Santa Ana y Sebastián de San José, a manos de locales de Tagolanda ${ }^{39}$. A esta misión le siguió otra tan sólo un año después, la de Juan del Caño y

37 Sánchez Pons, 2012: 81-101. En la estructura religiosa de las Molucas, todos los religiosos de este ámbito, y por consiguiente del norte de Sulawesi, tendrán como máximo responsable al obispo de Malaca. En una solución algo contradictoria, en las Molucas la administración civil dependía de Manila, mientras que la religiosa dependía de Malaca, situación que incluso se prolongará más allá de la ruptura ibérica, durando hasta el año 1654.

38 Adjudicación de la isla de Mateo y de Sanguilbasar y de todos sus naturales que allí habitan o vinieren aqui para que sean nuestras doctrinas, Ciudad del Rosario, 19 de marzo de 1610, AFIO, caja 21, leg. 3.

39 AFIO, caja 21, leg. 12, fol. 41. A la salida de Cauripa, bajo excusa de solicitar un salvoconducto para las fuerzas españolas, los nativos de Tagolanda asetean a Sebastian de San José provocándole la muerte, para luego apresar a Antonio de San José. 
Cristóbal Gómez, y hubo una tercera en 1612, a cargo de Pascual Torrellas y Benito Díaz. Su intensa actividad misionera les llevó a fundar iglesias en las poblaciones más importantes del norte de Sulawesi, no sólo en la localidad principal de Manado, sino que también, adentrándose en el interior, erigieron iglesias en las localidades de Banta y Cale (Blas Palomino y Diego de Rojas en 1619). La pujanza franciscana también motivó la presencia de jesuitas en el norte de Sulawesi. En el año 1617 documentamos la estancia en Manado de los jesuitas Scalamonti y Cosme Pinto, que tuvieron que ser relevados por enfermedad por Pero Gómez, quien permaneció hasta 1619.

Aunque los religiosos están presentes desde los primeros años del siglo XVII, su éxito más destacable se dará en la década de los cuarenta, gracias al gran número de conversiones logradas en los reinos de las islas de Sanguir (Calonga y Tabuca) con el envío de una comitiva evangelizadora franciscana cuyo resultado evangelizador también llegó a las poblaciones del norte de Sulawesi ${ }^{40}$.

La labor franciscana en estos territorios siempre se apoyó en el poder político español, participando en todas las expediciones que allí se dirigían. Como luego veremos, los testimonios de sus miembros serán de gran importancia para estudiar la presencia española en este territorio. Al convivir con los soldados españoles destinados en el norte de Sulawesi, serán testigos de primer orden de todo lo allí acontecido.

\section{Politicas: alianzas y fuerte-presidio}

Las primeras visitas que desde Ternate se hicieron a Manado en busca de recursos proporcionaron a los españoles un conocimiento directo de la zona. Frente a las pequeñas islas del Maluco, el norte de Sulawesi era un amplio territorio que debió despertar su curiosidad. Conociendo el tiempo de navegación y las fuerzas de las poblaciones locales, los dirigentes españoles del Maluco debieron plantearse la posibilidad de establecer alianzas con los jefes locales para conseguir aquello de lo que se carecía en las Molucas, e incluso si las fuerzas lo permitiesen, lograr el objetivo más ambicioso del control directo de la zona y la gestión propia de sus recursos. El primero en plantearlo fue Jerónimo de Silva, entre los años 1611 y 1617 gobernador del Maluco, que en 1614 en carta al gobernador de Filipinas, su primo Juan de Silva,

40 Relación de lo sucedido en Manados desde el año 1639 a causa de los agravios que hacian los españoles y por haber dado herida a uno de los principales levantaron más de diez mil indios, Manila, 4 de agosto de 1645, AFIO, caja 21, leg. 20. 
propone por primera vez la conquista de Manado ${ }^{41}$. A través de la linea marítima entre Ternate y Manado había recibido propuestas de alianza y de mutua colaboración de los caciques locales, e incluso una proposición para establecer un fuerte en Manado. El gobernador es consciente de que se está abriendo una nueva oportunidad histórica de expansión, pero que para llevarla a término resulta indispensable el envío de refuerzos de la metrópoli, ya que el hacerlo solamente con los efectivos allí presentes supondría descuidar las posiciones en las islas Molucas frente a unos holandeses muy bien asentados a tan sólo unos pocos kilómetros ${ }^{42}$.

Por parte española, la idea de la conquista de Manado surge en un contexto favorable. La victoria en la batalla de Playa Honda en 1610, donde se destruyó la escuadra holandesa que bloqueaba el comercio de Manila, creó un clima de optimismo general que culminó con la creación de una gran flota con la que se pensaba expulsar a los holandeses de Asia. En 1616 el enérgico gobernador Juan de Silva formó una gran escuadra de 42 barcos, 2.000 españoles y 3.000 nativos, con la que navegó hacia Malaca al encuentro de la escuadra holandesa que dificultaba el comercio luso entre Malaca y Macao. El objetivo era dar un fuerte golpe al poder marítimo de la VOC en Asia, para luego culminarlo dirigiéndose contra sus posiciones en Molucas. El naufragio frente al estrecho de Singapur hizo fracasar el plan y detuvo una posible expansión al sur de Filipinas. La gran armada nunca arribó a Molucas y el propio Jerónimo de Silva, que esperaba impaciente su llegada para visitar personalmente al rey de Manado, vio malograrse su tan ansiada aspiración ${ }^{43}$. Si el fracaso de la armada frente a Singapur desbarata cualquier intento de conquista, sí que al menos se envía una expedición con la intención de mantener acuerdos con los caciques locales. Sus propuestas de alianza, aunque de forma modesta, reciben respuesta con el envío en 1616 de seis soldados, seis manilas y dos franciscanos (Gregorio de San Esteban y Pedro de los Cobos). El envío, que fue para atender la petición del rey de Bohol, acabó mal con cinco españoles asesinados en Cauripa ${ }^{44}$. El soldado superviviente, junto a los

41 Sancho Rayón, 1868: 223. «Yo deseo en extremo la buena llegada de V. S. para que ocupemos esta isla que tiene según dicen más de nueve ó diez mil indios: quieren muy mal a los holandeses».

42 Aunque también frecuentan la costa norte de Sulawesi, la ausencia de especias hace que tengan poco interés por establecerse. Una expedición holandesa en Manado en 1615 procedente de Siao rechaza el ofrecimiento de dejar soldados en Manado por no poner en peligro una posible alianza con Ternate. Henley, 2004: 90.

43 Fernández Duro, 1895, vol. 3: 393.

44 AFIO, caja 21, leg. 12, fol. 48. «En el camino de Cauripa a Bohol se tomó una caracoa pequeña 5 españoles y 6 indios manilas de servicio, más un mestizo sangley que resultó ser 
dos religiosos, que se salvaron del ataque al ir en otra embarcación ${ }^{45}$, volverá a Ternate al cabo de un año ante el poco fruto de su evangelización.

El fracaso no desanima y el sucesor de Jerónimo de Silva, Lucas de Vergara y Gaviria, que llega en 1617, continúa con la política de su antecesor, siendo partidario de establecer alianzas con estos jefes. Envía otra expedición a Manado, algo más numerosa que la anterior, y lo hace además con ánimo de permanencia: 10 soldados al frente del entretenido Francisco Meléndez ${ }^{46}$, los jesuitas (Scalamonti y Pinto) ${ }^{47}$ y los franciscanos (Diego de Rojas y Juan Lego). Sus testimonios relatan que la situación es de gran tensión, de lucha entre la capital Manado y los olifares del interior. Pese a ello, se establece una guarnición española estable en el poblado de Manado. Según testimonio del jesuita Scalamonti, se les asignó un lugar en el poblado para la construcción de una iglesia, así como de un alojamiento para la expedición española. Dos años después los dos jesuitas tuvieron que volverse por enfermedad a Ternate, pero los soldados y los franciscanos permanecieron $^{48}$.

En marzo de 1619, una embajada de Ternate al reino amigo de Macasar hace escala en Manado. Tres de los seis franciscanos que van en ella se quedan aquí. Entre estos tres últimos va el franciscano Blas Palomino, que nos informa del fuerte-fortaleza creado dos años atrás. Su testimonio es vital para saber de primera mano la situación de la fuerza española. El capitán Francisco Meléndez, junto a un grupo de religiosos, soldados y pampangos, residen en el pueblo de Manado. En su crónica relata la llegada a Cale y su viaje por los diferentes pueblos del interior: Cacascasen (Kakaskasen), Tomun (Tomohon), Sarranson (Sarongson), Tonbani (Tanawangko), La Laguna (Tondano) y Las Quemas (Kema). Junto a dos soldados residirá en Tondano, para acabar volviendo otra vez a Manado, donde fijará finalmente su residencia. Para el religioso el gran problema es la escasez de soldados. La pequeña fuerza española que reside en Manado es una pequeña guarnición establecida en su puerto, pero a su alrededor hay multitud de tribus locales, cada una con su propio caudillo, en continuos enfrentamientos internos, y con escasez de grandes líderes, que cuando surgen son fácilmente revocados por los propios

un traidor, el cual había estado anteriormente en Bohol con los portugueses conociendo a una mujer de Bohol, cuyo marido que se encontraba en Cauripa quiso venganza habiendo lucha».

45 Sancho Rayón, 1868: 364.

46 AFIO, caja 21, leg. 12, fol. 89. Llegó a Molucas con posición de entretenido (con sueldo pero sin cargo) en el socorro de fecha 28 de diciembre de 1616.

47 Aernsbergen, 1925: 18.

48 Ibidem: 19. 
miembros de su tribu ${ }^{49}$. Blas Palomino lo tiene claro: o se trae una fuerza mayor a Manado para poder imponer un control político en la zona o no hay nada que hacer en relación con la conversión y control del territorio. La guarnición de Manado era muy escasa y su poco número no imponía respeto entre los locales ${ }^{50}$. Desmotivado por el poco fruto conseguido (su prédica cristiana tampoco es aceptada en muchos pueblos del interior por miedo al enojo de sus dioses) se plantea volverse a Ternate, y aunque el capitán Francisco Meléndez le da la razón, le invita a quedarse debido a que la guarnición española va a permanecer aguardando acontecimientos, confiando en que las cosas cambien y a la espera de noticias de Ternate. A 23 junio 1619, pese a las dificultades Blas Palomino se queda en Manado aunque los otros dos religiosos junto con el capitán Meléndez regresan a Ternate. La estancia de Blas Palomino acabará mal, martirizado en $1622^{51}$.

El asentamiento español en Molucas gozaba de cierta estabilidad a través de la tradicional alianza con el sultán de Tidore y el atento control sobre el sultán de Ternate. El mantenimiento de las alianzas sobre las élites sociales de la zona garantizaba la soberanía sobre todos sus súbditos. Por contra, en Minahasa la situación es diferente debido a la ausencia de un gran poder central y la existencia de numerosos pequeños caciques en continuo estado de guerra que van a dificultar el control español sobre este territorio. Esta inestabilidad política será el gran problema de los españoles. El conseguir el poder sobre Manado no aseguraba el control sobre todo el territorio de Minahasa. Había que ir sometiendo a todos los pueblos del interior y para ello hacía falta un número de efectivos imposible de obtener, ya que si se sacaban de las fuerzas de Molucas se corría el riesgo de que los holandeses tomasen las posiciones españoles. Los refuerzos que venían de Manila a través de Nueva España, eran insuficientes, siendo ya un éxito el que sirviesen para reponer la alta mortalidad de las fuerzas españolas del Maluco.

Las autoridades son conscientes de la dificultad de las Molucas y asumen que todo intento de control de la zona pasa por el envío directo de refuerzos de la metrópoli. Así lo expone ante el monarca el franciscano Cristóbal Gómez, que en 1615 llega a Madrid procedente de Sulawesi con el objetivo de

49 AFIO, caja 21, leg. 11, fol. 1. «si no les parecen bien lo que ellos hacen no les obedecen y así hay tantas cabezas como hombres libres y con ello otra dificultad, que no quiere hacer ni determinar nada un pueblo sin todos los demás».

50 Ibidem, fol. 3. «es menester sujetarlos y ponerles debajo de leyes y gobierno (...) que aquí si no hay más fuerza en Manados que ellos teman que no dejarán estar en su tierra religiosos».

51 Martínez, 1756: 176. 
pedir ayuda al monarca para frenar la expansión holandesa en las Molucas ${ }^{52}$. Pero no tiene éxito: la ayuda inicial compuesta de seis galeones y 1.500 soldados al mando del futuro gobernador de Filipinas Alonso Fajardo acabará dirigiéndose a Alemania, en ese mismo año, para sofocar las revueltas contra el emperador Fernando $\mathrm{II}^{53}$. Cuatro años después, en diciembre de 1619, se decide el envío de una escuadra para Molucas, que desgraciadamente fracasa al poco de zarpar a causa de las tormentas: el 3 de enero de 1620 un naufragio frente a las costas de Cádiz acaba con la flota. La expedición, al mando de Lorenzo de Zuazola, tenía previsto seguir la ruta por el cabo de Buena Esperanza, estando compuesta de 1.792 hombres (entre ellos 1.000 soldados y 732 marineros), la mayoría de los cuales murieron en el naufragio (entre ellos el propio Cristóbal Gómez) ${ }^{54}$. Otra vez los refuerzos necesarios para acometer políticas más ambiciosas en Molucas siguen sin llegar. Por segunda ocasión un naufragio desbarata la llegada de unos refuerzos que permitiesen contrarrestar el poder holandés e impulsar el posible dominio sobre Sulawesi. Los naufragios de Juan de Silva en Singapur de 1616 y de Lorenzo de Zuazola de 1620 frente a las costas de Cadiz, hicieron que en Manado no hubiera más que una pequeña guarnición de unas decenas de soldados a la espera de acontecimientos, con poca posibilidad de acción y más bien como declaración de intenciones, representando de forma simbólica las aspiraciones españolas de alianza y amistad con los pueblos de Minahasa.

En diciembre de 1621, el nuevo gobernador de Filipinas, Fajardo de Tenza, proyecta un novedoso enfoque estratégico sobre la zona: la creación de otra base logística en la Isla de Mateo ${ }^{55}$. Se trataría de ocupar una isleta en la punta nordeste de Sulawesi para dar soporte a una nueva ruta a Ternate. Incluiría construir un fuerte para además poder controlar el paso de naves enemigas, obtener víveres (carne y arroz) y servir de soporte al socorro en ambas direcciones. Fajardo de Tenza se refiere al estrecho formado por la actual isla de Pulua Lembeh y la ciudad de Bintung, situado en la costa oriental (la opuesta al acceso tradicional que se hacía por Manado, llamado por los españoles el estrecho de Santa Margarita), cerca de la actual población de Kema. El nuevo gobernador quiere impulsar la política en el Maluco,

52 Cristóbal Gómez (Cristóbal Ruiz en otras fuentes), fraile franciscano cuya presencia ya se documenta en 1611 en Sulawesi, a donde viajó nada más conocer el martirio de sus hermanos de orden Antonio de Santa Ana y Sebastián de San José. Estuvo en Bohol en labor misionera con el objetivo de continuar la tarea que sus hermanos no pudieron realizar. Su estancia no fue muy larga ya que por enfermedad tuvo que regresar a Ternate en 1613.

53 Colín, 1663: 159.

54 Gil, 1992, vol. 2: 190-193.

55 AGI, Filipinas, 7, R. 5, N. 65, fol. 14. 
y en este año de 1621 el socorro llega con destacados refuerzos (120 nuevos soldados se incorporan a las fuerzas de Ternate y Tidore) ${ }^{56}$. También se tiene en cuenta la petición por parte local de más soldados, tras haber sido retirados los que estaban en Manado por el maestre de campo Luis de Bracamonte. El fuerte de Manado se había desalojado temporalmente, pero el gobernador comunica haber dado orden de volver a enviar soldados y franciscanos, mandando al capitán Francisco Meléndez por su buena relación con los locales de esta zona al haber vivido varios años entre ellos. Se detalla el objetivo de esta misión: obtener no solo el permiso de los locales, sino también lograr su ayuda para la construcción del nuevo fuerte y tener elegido el sitio para cuando el gobernador pueda enviar gente. Un año después, en 1622, Fajardo de Tenza vuelve a incidir en la necesidad de este proyecto y repite que había ordenado levantar ese fuerte-almacén, pero que desgraciadamente no se había realizado porque la galera destinada con tal fin se había perdido en combate ante los holandeses. No obstante, asegura que lo volverá a intentar con un nuevo envío ${ }^{57}$. Y así lo hace mediante nueva carta fechada en agosto de 1623, dando orden directa a Pedro de Heredia, gobernador del Maluco (1623-1636), de no cejar en construir ese fuerte en la costa oriental ${ }^{58}$. Pero Pedro de Heredia, que llega a Ternate con una fuerza considerable para poder llevar a cabo el proyecto de la base en las Célebes ${ }^{59}$, no parece tener el mismo interés de sus antecesores en extender la influencia española más allá de las Molucas. Al tener que hacer frente a las rebeliones locales impulsadas por el sultán de Ternate, siente que sólo puede aplicar una política defensiva ante los holandeses. Bajo la excusa de no ver correspondidas sus peticiones de ayuda ${ }^{60}$, nunca llegará a acometer el fuerte en el estrecho de Santa Margarita ${ }^{61}$.

El sustituto de Fajardo de Tenza, el gobernador Niño de Távora, comunica a Felipe IV que el fuerte para controlar el estrecho de Santa Margarita no

56 Ibidem, fol. 10.

57 AGI, Filipinas 7, R. 5, N. 67, fol. 7.

58 Rodríguez, 1984, vol. 17: 30.

59 Sloos, 1898: 90. Una flota de cinco navíos, dos galeras y tres pequeñas fragatas.

60 Carta de Niño de Távora con noticias de Terrenate de Herrera, Manila, 20 de julio de 1620, AGI, Filipinas, 20, R. 19, N. 122, fol. 2. Cuando él pide que traigan de la India portuguesa por lo menos 200-300 hombres y sólo habían llegado 61 soldados de refuerzo. También se excusa de que se le habían prometido ocho galeras y que únicamente había podido disponer de dos.

61 Pérez, 1914: 627. El militar designado para la misión, el capitán Meléndez, es enviado en 1624, junto a seis soldados más y el franciscano Diego de Rojas, a la isla de Siao para ayudar en el enfrentamiento que su rey tenía con la isla vecina de Sangil Basar. 
se ha construido. Pedro de Heredia no lo ha llevado a término por no considerarlo prioritario, aunque quiere compensarlo reforzando la presencia española en el otro lado de la isla, para lo que pide al gobernador cincuenta hombres para ocupar el antiguo fuerte de Manado, sufragando su coste a través de la posibilidad de adquirir arroz ${ }^{62}$. Encontramos la respuesta de Felipe IV en un documento de 1627 en el que propio rey le da permiso para retomar el fuerte de Manado, prometiendo el envío de ayuda y armas ${ }^{63}$. Aunque el fuerte del estrecho de Margarita nunca se llevó a cabo, en cuanto a Manado el vínculo o alianza política tradicional se mantuvo. Pero los tiempos están cambiando al norte de Filipinas. En 1626, el establecimiento holandés en Formosa provoca el traslado de los acontecimientos hacía un nuevo frente norte que hace que las Molucas vayan perdiendo importancia y oportunidades de refuerzos ${ }^{64}$. Desde la corte española tampoco se apostó fuertemente por las Filipinas. Aunque Felipe IV decidió en 1624 la puesta en marcha de una gran flota de 3.000 personas entre soldados y marineros para salir de España en el verano de 1625 con destino al Pacífico, finalmente se decidió enviarla a Flandes, prefiriendo luchar con los holandeses en su propio país que en las lejanas tierras filipinas ${ }^{65}$.

En la década de los 30 la alianza siguió firme con Manado, como así lo prueba el envío en 1636 del hijo del rey de Manado (junto a un hijo del rey de Siao) al colegio jesuita de Manila para ser educado y tutelado por las autoridades españolas. También en 1637 el rey de Manado solicitó ayuda militar al nuevo gobernador del Maluco, Pedro de Mendiola, para sofocar una rebelión interna ${ }^{66}$. En ese momento la fuerza de las Molucas constaba de 570 soldados españoles y una fuerza auxiliar de 200 indios pampangos ${ }^{67}$. El número de efectivos casi 40 años después de la conquista de Pedro de Acuña apenas había aumentado. Los refuerzos difícilmente bastaban para cubrir las bajas que se producían en estas islas. Además, en 1637 se produjo una gran campaña militar en Mindanao (contra el sultán Corralat) ${ }^{68}$, a la que seguirá

62 AGI, Filipinas, 20, R. 20, N. 140, fol. 1.

63 Respuesta a Niño de Távora sobre asuntos de gobierno, Madrid, 3 de septiembre de 1627, AGI, Filipinas 329, L. 3, F. 136R-140R.

64 Para la presencia española en Formosa. Borao Mateo, 2014.

65 Gil, 1992, vol. 2: 209.

66 Blair y Robertson, 1905, vol. 27: 313 .

67 Fernández Duro, 1895, vol. 4: 420-421. Tomado del Memorial del Procurador D. Juan Grau y Monfalcón.

68 Sucesos de Filipinas contra Mindanao, 1637, Archivo Histórico Nacional, Madrid (AHN), Diversos-Colecciones, leg. 26, N. 70. 
otra contra Sulú en $1638^{69}$. Ambas operaciones supusieron un gran desgaste de fuerzas y recursos por la necesidad del envío de soldados y del establecimiento de fuertes en ambas zonas. Pese a todo, la presencia de soldados en Manado se mantiene, pues aunque escasa e intermitente, siempre debió haber una guarnición que testimoniara la alianza entre Manado y España. Si esta guarnición no estaba, por lo menos se mantenía una comunicación regular entre Ternate y Manado que no hiciera romper la alianza. Un documento fechado en 1639 nos informa de una carta del sargento mayor de las fuerzas del Maluco, Francisco Fernández, fechada en Manado y remitida al gobernador del Maluco, Pedro de Mendiola, en la que los locales volvían a pedir religiosos y a ofrecer vasallaje al rey de España ${ }^{70}$.

En la década de los 40, la guarnición española que sigue en Manado se enfrentará ahora a la rebelión local más violenta que se haya producido hasta el momento: el alzamiento del 10 de agosto de $1644^{71}$. Unos años antes habían llegado a Sulawesi procedentes de las islas Sangir dos franciscanos: el fraile Lorenzo Garralda y el padre Juan Iranzo. El desencadenante de la gran rebelión fue el maltrato dado por algunos soldados a la población local. El padre Iranzo relata cómo un soldado español hirió al jefe del pueblo de Tomun $(\text { Tomohon })^{72}$. Este agravio provocó la rebelión de sus parientes. Durante la noche, los hijos del herido convocaron a las otras tribus para degollar a todos los españoles. El levantamiento tuvo el resultado de 19 españoles muertos y $22 \operatorname{presos}^{73}$. Entre las víctimas se encontraba el hermano Garralda, quien, advertido de la rebelión y aun teniendo tiempo para huir, decidió quedarse para acabar siendo alanceado, decapitado y puesto en medio de la plaza de Cale, donde los locales hicieron danzas en torno a su cadáver ${ }^{74}$. Los pocos españoles supervivientes consiguieron refugiarse en la playa, donde construyeron con las maderas del convento una pequeña fuerza. Así estuvieron resistiendo durante ocho meses hasta que intentaron escapar en una embarcación pequeña con la que pretendían alcanzar Ternate. Un viaje del todo irrealizable para esa embarcación, en el que hubieran muerto ahogados, si no hubiese sido

69 Idem. En la campaña de Joló, que fue comandada personalmente por el gobernador Hurtado de Mendoza, se movilizaron unos 600 españoles y 3.000 nativos reclutados entre las diferentes provincias filipinas.

70 AFIO, caja 21, leg. 20, fol. 1.

71 Huerta, 1855: 684.

72 AFIO, caja 21, leg. 20, fol. 5. «El año de 1644 continuando los soldados sus ordinarios agravios y vejaciones, uno de ellos dio una herida al mayor principal del pueblo de Tomún donde yo asistía».

73 Juan de la Concepción, 1788, vol. 6: 178.

74 AFIO, caja 21, leg. 20, fols. 6-7. 
por la ayuda de Buntuán, el rey de Calonga, quien los rescató en las aguas del norte de Sulawesi. Los españoles sobrevivientes fueron acogidos por los reyes de Tabuca y Calonga, para más tarde en una embarcación fletada por el rey Buntuán llegar a Ternate.

La rebelión local y el Tratado de Westfalia parecen poner fin a la presencia española en Manado y facilitar la llegada de los holandeses a la zona, pero ello no ocurre de forma total ni inmediata. Pese a la rebelión, los españoles seguirán permaneciendo en el norte de Sulawesi y el relevo holandés no se produce tan rápidamente ni con tanta facilidad como cabría esperar. El acuerdo de Westfalia estipulaba que los españoles no podrían extender sus dominios en Molucas, lo que conllevó que el gobierno español no invirtiese ni hiciera más gastos en la zona de aquí en adelante ${ }^{75}$. Pese a esto, muchos de los españoles allí presentes se resistieron a que la influencia hispana sobre los pueblos locales empezase a declinar y se rompieran las alianzas conseguidas años atrás. Comprobamos cómo Manado sigue siendo destino de expediciones militares y estancias españolas ${ }^{76}$. En 1652 desde Ternate se manda una expedición de castigo de rebeldes al mando del capitán Bartolomé de Cosar, y su estancia se prolonga al menos por un año ${ }^{77}$. Dos años después, el 16 de julio 1654, se firma un nuevo acuerdo de paz con Manado: documentamos una carta del gobernador Manrique de Lara en la que dice que hay paces firmadas con los reyes de Macasar, Tidore, Calonga y Manado ${ }^{78}$. Volvemos a tener testimonios de la presencia española en Manado para el año 1656, cuando las fuentes franciscanas registran otra expedición al mando del sargento mayor Juan de Ytamarren (en la que irá el franciscano fray Pedro de San Buenaventura) $)^{79}$.

Sin embargo, y a pesar de la influencia española, los holandeses empiezan a ambicionar el control directo de este territorio, y en 1657 establecen su primer asentamiento en Manado. Aprovechando una petición local de ayuda, inician la construcción de su primer fuerte en la zona, desde donde intentarán romper la alianza que los locales aún tienen con España ${ }^{80}$. Manado, recelosa del poder de Siao, el aliado por antonomasia de los españoles en la zona,

75 Martínez Shaw, 1999: 117-130.

76 Godée-Molsbergen, 1928: 10-15.

77 Peticiones y recaudos para los religiosos de Terrenate en que se hace constar cómo la provincia de Manados ha sido desde el principio administrada por los franciscanos, Ternate, 12 de mayo de 1657, AFIO, caja 21, leg. 26, fol. 2.

78 Prieto Lucena, 1984: 101.

79 Carta del Padre Trujillo al Provincial Alonso de San Francisco, Ternate, 15 de junio de 1655, AFIO, caja 21, leg. 25, fol. 1.

80 Dam, 1931: 76. 
buscará en los holandeses un apoyo que contrarrestase el fuerte vínculo entre Siao y España. Cuatro años después, en 1660, la influencia y la presión holandesa ya se hace notar y Manado rompe su alianza con España. El gobernador Manrique de Lara informa al monarca de que, ayudados por el holandés, se habían rebelado contra los soldados españoles que allí seguían manteniendo la posesión, el dominio, señorío y potestad del monarca hispano ${ }^{81}$.

Si bien es cierto que los holandeses consiguen que en 1660 Manado rompa con España, algunas tribus del interior todavía se alinean junto a los españoles $^{82}$. Se trata de los habitantes de La Laguna o Tondano ${ }^{83}$, a unos 30 kilómetros de Manado, la mayor población de Minahasa y la que mayor afinidad tuvo siempre con los españoles. Los motivos de esta complicidad los podemos encontrar en diferentes razones, la principal de las cuales sería su posición de tributarios de la etnia de Tonsea ${ }^{84}$ (más al norte y responsable de la rebelión anti-española de 1644), pues así su alianza con los españoles reforzaría su posición frente a los antiguos señores. El gobernador holandés de las Molucas, Roberto Padtbrugge, remarca que son los únicos habitantes del norte de Sulawesi que muestran orgullo de ser monógamos y que llevan el pelo corto cortado en redondo a la altura de las orejas, lo que también puede ser un indicio de su buena adaptación a las costumbres españolas ${ }^{85}$. Serán los últimos en aceptar el dominio holandés en la zona, protagonizando una gran rebelión en 1663 que impidió a los holandeses conseguir el arroz que necesitaban y que no en vano era el principal motivo de su interés por el norte de Sulawesi ${ }^{86}$. Los holandeses señalan como el gran instigador de esta rebelión al jesuita Francisco de Miedes $^{87}$, quien tras la evacuación española de las Molucas fue capaz de reclutar 50 seguidores en Ternate ${ }^{88}$ para vía Siao llegar a Sulawesi. El jesuita estaría en el año 1663 en Tondano ofreciendo ayuda para luchar contra los holandeses, proporcionando pólvora y alentando la posibilidad de establecer de nuevo un fuerte cerca de la zona

81 Carta de Manrique de Lara sobre asuntos de guerra, Manila, 20 de junio de 1671, AGI, Filipinas, 9, R. 2, N. 34, fol. 33.

82 Henley, 1993: 39-60.

83 Padtbrugge, 1866: 307. La Laguna correspondería a una gran población en torno al actual lago Tondano. Su nombre Ton-dano significaría pueblo del agua, su rival la tribu Tonsea (Ton-sea, correspondería al pueblo de la catarata).

84 Wigboldus, 1987: 76.

85 Idem. Padtbrugge, 1866: 320.

86 Wigboldus, 1987: 69.

87 El padre Francisco de Miedes había llegado a Molucas en 1655, alternando entre Ternate y Siao.

88 Chijs, 1893: 290. 
de Las Quemas (Kema), donde ya se había establecido una iglesia en décadas anteriores (la zona más oriental del norte de Sulawesi y más lejana a Manado). El mando holandés en Manado advierte de la necesidad de aliarse con el pueblo de Las Quemas para evitar que éstos puedan volver a llegar a un acuerdo con los españoles ${ }^{89}$.

En 1662 se tomó la decisión de evacuar las Molucas ante la amenaza del pirata chino Koxinga sobre Manila. La evacuación se hizo efectiva en mayo de 1663, cuando se desmanteló el presidio de Ternate, y aunque se dijo a los holandeses que la salida era temporal, la vuelta ya no fue posible. Su situación, al margen de la amenaza de Koxinga, era ya de por sí muy débil, la isla era improductiva y las fuerzas españolas seguían sin resolver su problema de suministros ${ }^{90}$, además de los casos de deserción y de paso a las filas holandesas. El gobernador del Maluco, Francisco de Atienza, destruyó las fortalezas y los almacenes e incendió las casas y conventos para que no pudieran ser aprovechados por los enemigos. Antes de abandonar las Molucas quisó dejar claro que por derecho de guerra se había tomado la soberanía sobre Ternate y que en virtud de la Paz de Münster, dicha soberanía debía ser respetada ${ }^{91}$. Los holandeses, al encontrarse el camino despejado, eliminaron todos los claveros de las diferentes islas para que no pudieran hacer competencia a las suyas y aprovecharon los materiales de los presidios españoles abandonados para reforzar sus propias construcciones. La evacuación de Ternate supuso la sentencia final sobre Sulawesi. La salida española de las Molucas despejó el camino a los holandeses para tomar el control directo sobre el norte de Sulawesi. En 1666 construyeron en Manado su fuerte definitivo en piedra (Fort Amsterdam), que sustituyó al anterior, convirtiéndose en el centro del poder holandés en la zona.

Tras la evacuación de las Molucas, el último reducto español se concentró en el tradicional aliado Siao, donde desde 1671 residía una pequeña fuerza de soldados españoles. Fueron enviados más como símbolo de continuidad de la alianza con los locales, que no querían renunciar a su cristianismo (junto a los soldados estaban tres miembros de la compañía de Jesús), que como posibilidad de mantener un fuerte de defensa militar ${ }^{92}$.

89 Aernsbergen, 1925: 26.

90 Prieto Lucena, 1984: 134.

91 Colín, 1663: 811: «porque aunque se retiraban las armas el Rey nuestro señor retenía en si el dominio, señorío y potestad y propiedad que como legítimo Dueño y Señor tenía en aquel territorio en todas sus plazas, fuerzas y fortificaciones antes de dicho retiro».

92 AGI, Filipinas, 23, R. 17, N. 55, fol. 3. «Residen allí sin presidio, ni fortificación de piedra ni artillería, ni tienen otras armas que las ordinarias de arcabuces y mosquetes». 
El reducto de Siao fue un problema para los holandeses. Sin legitimidad para ocuparlo (ya que según lo dispuesto en el Tratado de Münster era lugar de soberanía española), su cercanía a Manado les hacía temer que los pocos españoles instigasen a sus antiguos aliados del norte de Minahasa. De hecho, en julio de 1673, documentamos una visita del mando mayor de la fuerza de Siao, el capitán Andrés Serrano, junto al jesuita Francisco de Miedes, al Fort Amsterdam de Manado. Acuden para entrevistarse con el gobernador de las Molucas, Cornelis Frank (1672-74), firmando un acuerdo por el que ambas partes no volverían a levantarse en armas ${ }^{93}$. Finalmente, los holandeses lograrán que Ternate declare la guerra a Siao. En 1677 una expedición holandesa bajo la supervisión del gobernador de Molucas, Robert Padtbrugge, acompaña al rey de Ternate a la conquista de $\mathrm{Siao}^{94}$. Así se consigue acabar con el último reducto español en la zona, expulsando a los españoles del fuerte Santa Rosa, el último puesto español de las Célebes ${ }^{95}$. Fue una operación llevada a cabo por fuerzas de Ternate, sin que oficialmente la VOC llegará a participar militarmente, o eso al menos se pretendía hacer ver para no incumplir el Tratado de Münster. Disponemos del testimonio de unos de los jesuitas que allí se encontraban, el padre Manuel Español, que residía junto a sus compañeros, Carlos Sarcoti (procedente de Flandes) y Jerónimo de Cebreros (el padre Miedes había recibido la orden de regresar a Filipinas, muriendo en Iloílo en 1674). La fuerza estaría compuesta de 25 soldados, 13 españoles y 12 pampangos, al mando de Andrés Serrano ${ }^{96}$. Bajo la coartada de una cuestión de legitimidad matrimonial ${ }^{97}$, los holandeses encontraron la excusa para justificar el ataque del sultán de Ternate a Siao, expulsando a la última fuerza española 71 años después de la llegada de la expedición de Pedro de Acuña. La VOC procedió rápidamente a cortar los claveros de la isla para salvaguardar su monopolio del clavo.

\section{Consecuencias y Balance Final}

A la salida española del norte del Sulawesi, le sucedió la llegada de los holandeses que, a diferencia de los españoles, iniciaron un fuerte proceso de

\footnotetext{
93 Jacobs, 1984, vol. 3: 679.

94 Robidé van der Aa, 1867: 100. Haciendo antes escala en su aliado Manado para sumar efectivos a la operación.

95 Aritonang y Steenbrink, 2008: 67. Juan de la Concepción, 1788, vol. 7: 260.

96 Padtbrugge, 1867: 193. Según el diario de Padtbrugge el fuerte español estaría en la costa este de la isla, cerca de la población de Oele (Ulu).

97 Herrera Reviriego, 2014: 539-544.
} 
colonización, que con el tiempo hizo que el territorio de Manado fuera conocido dentro de Indonesia por su fuerte grado de aculturación neerlandesa. La evacuación española de las Molucas supuso el golpe definitivo de la presencia en Sulawesi. Sin rival europeo, a los holandeses les fue relativamente cómodo controlar todo el norte de Sulawesi, incluyendo las islas más septentrionales. Desde su fuerte en Manado lograron imponer sus condiciones a los diferentes pueblos de la región, bien por acuerdo o haciendo uso de su fuerza militar. La anterior presencia española, aunque no fuera muy numerosa, sirvió de contrapeso a las aspiraciones holandesas, pues los pueblos locales tuvieron un posible aliado con el que poder oponerse a Holanda. Desalojados los fuertes de Molucas, Holanda pasó a ser el único árbitro y señor de todo este territorio.

No obstante, la presencia de soldados y religiosos españoles durante algo más de 50 años, nos hace preguntarnos si dejó algún poso o tuvo algunas consecuencias en estos territorios. A nivel de restos materiales el rastro en imperceptible, pues las construcciones como el fuerte de Manado o las iglesias de Banta y Cale, al ser hechas en madera, no debieron durar mucho tiempo. Es en el campo de la filología es donde podemos encontrar ecos de esta presencia. A través de los misioneros protestantes creadores de los primeros diccionarios de las lenguas de la zona a finales del siglo XIX, encontramos el uso de palabras de origen español. En el manado-malais, también conocido como lengua minahasa durante el período de administración holandesa (melaju-pasar), encontramos palabras de claras reminiscencias castellanas: pasiar (pasear), toki (tocar), Blanda (Holanda), horas (tiempo), kintal (terreno), pesta (fiesta), kawalo (caballo) o liquidar (matar) ${ }^{98}$. Además de la lengua, el actual nombre de Kema, población en la costa oriental del norte de Minahasa, parece proceder del original español de Las Quemas, denominación que usaban los españoles para designar la zona más oriental de Minahasa.

A modo de conclusión podemos decir que el comienzo de la ocupación española fue consecuencia directa de su cercanía a Ternate. La soberanía española en el Maluco a partir de la expedición de Pedro de Acuña de 1606 propició que un territorio al que se le había prestado poco interés pasase a adquirir cierta importancia estratégica desde una triple perspectiva: económica (como fuente de suministros que remediase la carestía crónica de los fuertes de Ternate y Tidore), política (como área de potenciales aliados) y religiosa (como tierra de evangelización católica).

Si bien al inicio desde las altas instancias no hubo una línea política de establecimiento en este territorio, las informaciones que iban llegando desde

98 Niemann, 1870: 76-120. 
el Maluco hicieron que desde España se llegasen a plantear estrategias de control, como así reflejan las órdenes que Felipe IV envió para la construcción de un fuerte en la costa oriental (que finalmente no se llevó a cabo por decisión personal del gobernador del Maluco, Pedro de Heredia). La lejanía de este territorio impidió la puesta en marcha de un proceso de colonización. Los posibles recursos que se debían enviar desde Nueva España vía Manila, apenas cubrían las necesidades de los fuertes de las Molucas, con lo que difícilmente quedaban efectos para enviarlos a otras plazas más lejanas.

Hubo un interés real en la zona y a ello obedece el hecho de mantener durante varias décadas una guarnición española en Manado, aunque con un número insuficiente de efectivos para acometer planes más ambiciosos de conquista. La falta de medios hizo que el fuerte en Manado tuviera más carácter diplomático que de puesto de control. Pero, aunque la presencia española en Sulawesi no fue continua (tal como ocurrió en las islas de Ternate y Tidore), la comunicación con el norte de Sulawesi siempre existió y la navegación de pequeñas embarcaciones con Manado, Siao y las islas Sangir nunca se interrumpió, siendo posible el intercambio de noticias, mercancías y personas entre ambos lados del mar de Molucas. Si bien la presencia española apenas ha dejado un legado o influencia en el territorio, queda por realizar estudios de mayor profundidad para ver si el alcance pudo ser mayor.

\section{BiBLIOGRAFÍA}

Aernsbergen, Anthonius van, "De Katholieke kerk en hare Missie in de Minahasa", BKI, 81 (S-Gravenhage, 1925): 6-55.

Aritonang, Jan Sihar y Steenbrink, Karel, A History of Christianity in Indonesia, Leiden, Brill, 2008.

Blair, Emma Helen y Robertson, James Alexander, The Philippine Islands: 16361637, vol. 27, Cleveland, H. Clark, 1905.

Borao Mateo, José Eugenio, Spaniards in Taiwan, 2 vols., Taipei, SMC Publishing, 2014.

Centenero de Arce, Domingo y Terrasa Lozano, Antonio, "El sudeste asiático en las políticas de la Monarquía Católica. Conflictos luso-castellanos entre 1580-1621", Anais de História de Além-Mar, IX (Lisboa, 2008): 223-266.

Chijs, Jacobus Anne van der, Dagh-Register gehouden int Casteel Batavia vant passerende daer ter plaetse als over geheel Nederlandts-India, Anno 1664, s'Hage, Batavia Landsdrukkerij, 1893. 
Colín, Francisco, Labor Evangélica, Ministerios Apostólicos de los Obreros de la Compañía de Jesús, Fundación y progreso de su provincia en las Islas Filipinas, Madrid, Joseph Fernández Buendía, 1663.

Dam, Pieter van, Beschrijvinge van de Oostindische Compagnie, 1639-1701, Deel 2.1., S-Gravenhage, Stapel, 1931.

Fernández Duro, Cesáreo, Historia de la Armada Española desde la Unión de los Reinos de Castilla y de Aragón, vol. 3., Madrid, Sucesores de Rivadeneyra, 1895.

Fernández Navarrete, Domingo, Tratados históricos, políticos, éthicos y religiosos de la monarquía de China, Madrid, Imprenta Real, 1676.

Gil, Juan, Mitos y utopías del Descubrimiento, vol. 2., Madrid, Alianza, 1992.

Godée-Molsbergen, Evehardus Cornelis, Geschiedenis van de Minahasa tot 1829, Weltevreden, Landsdrukkerij, 1928.

Henley, David, "A Superabundance of centers: Ternate and the Contest for North Sulawesi”, Cakalele, 4 (Manoa, 1993): 39-60.

Henley, David, "Conflict, Justice, and the Stranger-King Indigenous Roots of Colonial Rule in Indonesia and Elsewhere", Modern Asian Studies, 38/1 (Cambridge, 2004): 85-144.

Herrera Revierigo, José Miguel, Manila y la Gobernación de Filipinas en el Mundo Interconectado de la segunda mitad del siglo XVII, tesis Doctoral, Univ. Jaume I, 2014.

Huerta, Félix, Estado Geográfico, Topográfico, Estadístico, Histórico-Religioso de La Santa y Apostólica Provincia de S. Gregorio Magno, Manila, 1855.

Jacobs, Hubert, Documenta Malucensia, vol. 3, Roma, IHSI, 1984.

Juan de la Concepción, Historia General de las Filipinas, 14 vols., Manila, Ed. A. de la Rosa y Balagtas, 1788-92.

Laarhoven, Ruurdje y Pino Wittermans, Elizabeth, "From Blockade to Trade: Early Dutch Relations with Manila, 1600-1750”, Philippine Studies, XXXIII/4 (Manila, 1985): 485-504.

Leonardo de Argensola, Bartolomé, Conquista de las Islas Malucas al rey Felipe III, Madrid, Alonso Martín, 1609.

Martínez, Domingo, Compendio Histórico de la Apostólica Provincia de San Gregorio de Philipinas de Religiosos Menores Descalzos de San Francisco, Madrid, Viuda de Manuel Fernández, 1756.

Martínez Shaw, Carlos, "El imperio colonial español y la República Holandesa tras la Paz de Münster", Pedralbes: Revista d història moderna, 19 (Barcelona, 1999): 117-130. 
Morga, Antonio de, Sucesos de las islas Filipinas, México, 1609.

Niemann, George Karel, "Mededeelingen Omtrent de Alfoersche Taal van NoordOost Celebes", BKI, 17 (S-Gravenhage, 1870): 69-120.

Padtbrugge, Robert, "Beschrijving der zeden en gewoonten van de bewoners der Minahassa", BKI, 13 (S-Gravenhage, 1866): 304-331.

Padtbrugge, Robert, "Het Journaal van Padtbrugges Reis naar Noord-Celebes en de Noordereilanden”, BKI, 14 (S-Gravenhage, 1867): 105-268.

Pérez, Lorenzo, "Historia de las misiones de los Franciscanos en las islas Malucas y Célebes", Archivum Franciscanum Historicum, VII (Roma, 1914): 198-226, 424446 у $621-652$.

Prieto Lucena, Ana M., Filipinas durante el gobierno de Manrique de Lara, 16531663, Sevilla, Escuela de Estudios Hispanoamericanos, 1984.

Ramerini, Marco, La storia della presenza Spagnola nelle Isole Molucche: Le fortezze spagnole nella ísola di Tidore 1521-1663, Roma, Saggistica, 2008.

Robidé van der Aa, P. J. B. C., "De Vermeestering van Siauw door de Oost-Indische Compagnie", BKI, 14 (S-Gravenhage, 1867): 95-104.

Rodríguez Rodríguez, Isacio, Historia de la Provincia Agustiniana del Santo nombre de Jesús de Filipinas, vols. XVII-XVIII, Valladolid, Estudios Agustinianos, 19841986.

San Antonio, Juan Francisco, Franciscanos descalzos en Castilla la vieja: Crónica de la Santa Provincia de San Pablo, Salamanca, Santa Cruz, 1728.

Sánchez Pons, Jean-Noel, "Misión y Dimisión, Las Molucas en el siglo XVII entre jesuitas portugueses y españoles", Alexandre Coello de la Rosa, Javier Burrieza y Doris Moreno (eds.), Jesuitas e Imperios de Ultramar (siglos XVI-XIX), Madrid, Sílex, 2012: 81-101.

Sánchez Pons, Jean-Noel, “'Clavados con el clavo’. Debates españoles sobre el comercio de las especias asiáticas en los siglos XVI y XVII", Salvador Bernabéu Albert y Carlos Martínez Shaw (coords.), Un océano de seda y plata: el universo económico del Galeón de Manila, Sevilla, CSIC, 2013: 107-132.

Sancho Rayón, José León, Documentos inéditos para la historia de España, tomo LII, Madrid, Imprenta de la Viuda de Calero, 1868.

Santos Hernández, Ángel, Cristianismo en crecimiento, tomo III, Madrid, Eapsa, 1977.

Sloos, Dirk A., De Nederlanders in de Philippijnse wateren voor 1626, Amsterdam, De Wit, 1898.

Spate, Oskar H., El lago español, España, Casa Asia, 2006. 
Wigboldus, Jouke S., “A History of the Minahasa c. 1615-1680”, Archipel, 34 (París, 1987): 63-101.

Fecha de recepción: 10 de febrero de 2015.

Fecha de aceptación: 9 de marzo de 2015.

\section{The Spanish presence in the north of Sulawesi during the seventeenth century. A study of Spanish settlement in the north of Sulawesi in the face of local opposition and the Dutch threat (1606-1662)}

Spanish sovereignty over the Moluccas Islands (1606-1662) led to a relatively unknown episode in Spanish history involving the presence of Spanish soldiers in the north of the island now known as Sulawesi. The conquest of the Moluccas in 1606 marked the start of a period of frequent contacts between the Spaniards of the Moluccas and the tribes of nearby North Sulawesi. For several decades alliances were made and a small Spanish colony occupied the north of Sulawesi. The remoteness of the territory and the scarcity of resources were to make the consolidation of a Spanish colony impossible and were to be followed by Dutch colonization of this territory. However, far from being an isolated episode, this Spanish presence continued for almost seven decades, during which Spanish soldiers and members of the Church travelled and resided in a territory remote from the centre of power of Manila.

KeY words: Manado; Tondano; Celebes; Sulawesi; Ternate; Siau. 